\title{
Contemporary Sport as Media Spectacle: Mass Media and the Transformation of the Field of Sport
}

\section{Tony Schirato* and Noah Zhang}

Department of Communication, Faculty of Social Sciences, University of Macau, Avenida da Universidade, Taipa, Macao

\begin{abstract}
This article is concerned with the mass media-sport nexus, and its role in shaping and transforming the field of sport in what we can call its contemporary phase; this will be taken to refer to the last forty years or so, in which time the relatively incipient and equivocal relationship that sport developed with the mass media during the first sixty years of the twentieth century became a symbiotic relationship.
\end{abstract}

\author{
Publication History: \\ Received: May 25, 2015 \\ Accepted: September 07, 2015 \\ Published: September 09, 2015
}

\section{Keywords:}

Mass media, Sport, English, Revenue

\section{Introduction}

From its beginnings in mid-nineteenth century English public schools-inflected sport has tended to represent itself as autonomous, inalienable and utopian; both a world within itself (a space that allows people to escape from everyday seriousness) and a kind of exemplar of what the wider social field should be like (often articulated in terms of the notion of a level playing field). The field of sport continues to refer back to its foundational values, but these references have now taken on a variety of functions that would have been unimaginable or anathema to the English patrician classes of the 1860s, such as featuring in mass media promotional campaigns. It may "go without saying" [1], but it still needs to be said, that:

the popularisation of sport, down from the elite schools (where its place is now contested by the 'intellectual' pursuits imposed by the demands of intensified social competition) to the mass sporting associations, is necessarily accompanied by a change in the functions which the sportsmen and their organizers assign to this practice, and also by a transformation of the very logic of sporting practices which correspond to the transformation of the expectations and demands of the public in correlation with the increasing autonomy of the spectacle vis-à-vis past or present practice. The exaltation of 'manliness' and the cult of 'team spirit' that are associated with playing rugby - not to mention the aristocratic ideal of 'fair play'

- have a very different meaning and function for bourgeois or aristocratic adolescents in English public schools and for the sons of peasants or shopkeepers in south-west France [2].

This network of mass media-inflected relations and practices allowed sport to connect with, take advantage of and renew and promote itself through, 'outside' dispositions and promote itself through, 'outside' dispositions and imperatives: sport continues to commit to and perform in accordance with its foundational values, but it also functions as both a service industry and an extension of the mass media. One of the more explicit examples of this development is that most curious of phenomena, witnessed at rugby events such as the 'Wellington Sevens' competition in New Zealand where crowds, dressed up in outlandish costumes and performing in accordance with carefully choreographed moves and directions (signaled and activated by the presence of television cameras), watch themselves being watched by television audiences. In this article we will consider how the relationship between the field of sport and the (predominantly capitalist) mass media has been played out of the last forty years, and how this has transformed both the field sport and its place within and relation to the wider social field.

Prior to the Second World War the mass media had a limited relation with and impact upon the field of sport. Newspapers had reported upon and had become associated (through various forms of sponsorship) with sporting events since the last decade of the 19th century, and continued be tolerated, although generally kept at arm's length, by sports administrators. However generally (and most pronouncedly in Britain and the Commonwealth) the field of sport was highly suspicious of other forms of the mass media. Radio dominated live sports coverage in both the USA and the UK, but whereas in the United States television won audiences with its telecasts of boxing and college football in the 1940s and 1950s; it cut into radio audiences to the extent that while it had been an "essential part of daily life" in America in the 1930s, by the end of the 1940s "the average American listened to the radio for only twenty four minutes a day" [3], in Britain the changeover was a much more gradual process. This was partly due to the status and influence of $\mathrm{BBC}$ radio, but probably more so because of the relatively slow development of a national transmitter system: once this was in place growth was rapid, to the extent that whereas in the "early 1950s less than $5 \%$ of households" possessed television sets, by the 1970s "this was the proportion of those that did not" [4].

This did not at first translate into wide and consistent live television coverage of mass spectator sport in the UK. As we noted, there was a suspicion on the part of many sports administrators that such a move would have a detrimental impact on attendances: this had been the case in the USA with boxing telecasts, which had contributed to falls in attendances at Madison Square Garden of up to $80 \%$ in the 1940 s [5]. While there had been a remarkable post-war (and pre-television) increase in attendances at English soccer, cricket and rugby league matches, by the 1960s:

*Corresponding Author: Prof Tony Schirato, Department of Communication, Faculty of Social Sciences, University of Macau, Avenida da Universidade,Taipa, Macao, E-mail: tony.schirato@umac.mo

Citation: Schirato T, Zhang N (2015) Contemporary Sport as Media Spectacle: Mass Media and the Transformation of the Field of Sport. Int J Journalism Mass Comm 1: 112. doi: https://doi.org/10.15344/2349-2635/2015/112

Copyright: (c) 2015 Schirato et al. This is an open-access article distributed under the terms of the Creative Commons Attribution License, which permits unrestricted use, distribution, and reproduction in any medium, provided the original author and source are credited. 
the number of paying spectators was falling across the board, a trend that continued in the 1970s and beyond ... For 1969-70, for example, Football League attendances fell to 29.6 million, a drop of 28 per cent in twenty one seasons, with the low point coming in 1984-5 when only 17.8 million attended, down 56 per cent from the post-war boom. In county cricket, a decline was evident by the early 1960s with the 'nadir' reached in 1966 when ' 513,578 individuals went through the county turnstiles', a mere 22 per cent of the crowds in 1947. The rugby league Challenge Cup Final continued to draw large crowds ... but after the record crowd at Odsal for the 1954 replay, the fixture ... failed to fill Wembley on thirty occasions. A more noticeable decline was evident in the league fixtures: by 19689 , attendances had fallen to 2.7 million, a drop of 60 per cent over twenty one seasons ... This was a time of the game's catastrophic decline as a spectator sport ... (and) examples can be multiplied across the other spectator sports [6].

Martin Polley identifies a number of reasons for this trend, including increase in available leisure activities, a switch to individual sports participation, the primitive state of stadium facilities and hooliganism and crowd disorders; but clearly one of the most significant factors was "the increasing amount of television sport which allowed potential spectators to sample a greater variety of events than they could ever see live without having to pay or leave their own homes" [7]. The other side of the decline in live attendances from the 1960s onward was a concomitant development of (predominantly televisual) interest in established sports such as golf, tennis, athletics, horseracing and boxing, relatively minor sports such as snooker and darts, overseas sports (the NFL, Australian rules, Sumo wresting) and even nonsports ('professional wrestling', poker).

\section{Discussion}

Once this culture of and audience for televisual sport developed, it fed back into and influenced the field in a number of significant ways. At a very basic level, television more or less picked up and tied itself to certain sports and events and ignored others. Soccer, the Five/Six Nations, the British Open and Wimbledon already had mass audiences and high media profiles. In such cases, capital simply attracted capital: demographics widened; sponsorship, advertising and broadcast rights revenue poured in; and salaries and prize-money soared. Some lowprofile sports also benefited. Snooker and darts were both relatively static and small-space activities. The cameras could follow the action easily while also focusing intimately on the face and expressions of the players and the reactions of the crowd, and the commentators had time to presage, narrate and 'build up' every shot or move. This was perfect for creating and showing tension, suspense, drama and passion, and for promoting larger-than-life or eccentric characters; in other words, it was well suited to television. Sports such as squash, table tennis, badminton, sailing and athletic field events, on the other hand, suffered precisely because they weren't television-friendly. Squash, for instance, was both architecturally unsuitable (players could come between the ball and cameras placed behind or above the action), as well as being simply too fast for spectators to follow or for commentators to do much more than 'talk across' the action. Most tellingly, a great deal of time could be expended in a rally where the players hit the ball up and down the wall waiting for a mistake, and if the point went against the server then nothing had happened - and it had taken a long time to not happen. Contrast this with an NFL game, where each play can be anticipated, analysed, evaluated, contextualised (by the main commentators, special comments person, and sideline reporters) and broken down into multi-angled slow motion 'slices'; and where the frequency of time outs and changes of possession allows for the insertion of numerous commercial breaks. Faced with declining participation numbers and revenue, squash officials did everything to revamp the game for television, including introducing fluorescent balls and transparent walls and changing the scoring system, but nothing really worked: most squash events are in more or less the same position as FIFA in 1954, which gave away the television rights to the tournament in Switzerland "and considered itself lucky to get the publicity" [8].

There are numerous other effects and consequences of the televisual turn of sport. First, consider the issues of space and architecture and their relation to sporting events and crowds: contemporary stadia are designed and built not just with the game or even the attending spectators in mind (although they must have their own easily visible television screens for instant replays), but also to cater for the needs of sponsors, advertising and television cameras, and to encourage consumerism and consumption. In short, the shape and contents of stadia (a mixture of functionality and consumerist aesthetics) mirrors both the heterogenous nature of the field of sport itself, and the logics and imperatives of the mass media spectacle:

there are few construction processes as those involved in the building of modern stadiums. From space and seats and washrooms for tens of thousands of people, to retractable roofs, to $50 \times 80$

$\mathrm{ft}$ television screens suspended hundreds of feet in the air ... Postmodern stadiums are massive in size, even though their carrying capacity is not increased proportionately ... They are ... ambiguous in the sense that they merge their functions as sports facilities with provisions for banqueting, accommodation (hotels), rented offices, museums and merchandizing. The former mono-functional soccer stadium has given way to a multi-functional business facility ... the interior of the stadium is constructed in such a way that spectator 'sight lines' are unimpeded ... each individual should have a clear,

direct view of the action ... Stadiums, as important pieces of architecture, are constructed to be visually consumed ... Totally encircled and domed stadiums ... serve to divorce the stadium experience from the reality of the world around it. This increasing territorialization and commodification turns public space into private space and offers a more particularized and individualized means of visual consumption ... seeing thousands of other people gathered together in the same place at the same time to partake in a common experience gives one a sense of extended evaluation. One feels something when looking at a crowd of which one is a part. The crowd 'looks at' its self and 'reacts to' its self, which creates an everchanging experience of its self [9].

Perhaps the most significant aspect of this description/evaluation is the reference to what Baudrillard [10] would call the simulation of group identity, packaged as both performance and commodity. At a sporting event the crowd is constantly made aware that it is being watched by and through the mass media. It is prodded (through music, directions from the ground announcer and the antics of the mascot) into performing accordingly: it must be noisy, involved, interactive, demonstrative and passionate - in a carefully choreographed, timely and deliberate manner. In fact the responsibilities of the crowd start before they enter the stadium: colourful and eccentric hats, masks, clothes and scarves should be in evidence; faces painted; signs, flags and posters (preferably making some reference to the relevant 
television network covering the game) waved, and group chants and routines worked out and practiced. On the way to the ground the crowd starts to take shape and become productive: it is usually carefully streamed and articulated; vendors, hawkers, program sellers and samplers equip people with flags, rosettes, confectionaries and copies of team line-ups strategically encircled by advertisements; and the first chants, songs, bugle calls, challenges or banter churn out and up the atmosphere.

Once inside the stadium everything is done to 'warm the crowd up', with the same purpose as players going through their stretching and skills routines: there is constant pop music; the ground announcements reminding everyone of just how important the game is, what's at stake, and how valuable crowd support is to the team; and the television screen interspersing ads for products and upcoming games with stirring, larger than life scenes of players in action, brawls, controversies and past victories. The game and crowd performance is in the processes of being watched, textualised and disseminated worldwide (on local television screens, satellite networks, packaged highlights downloaded on digital phones, web site reports and upto-the-minute statistics, as newspaper and magazine articles), and has already been integrated into chronological and spatial rhythms and networks that extend way beyond the field of sport. The choice of stadium and the date of play may have been influenced by the proximity of other competing events and/or traffic and transport regimes; the starting time itself may be determined by the desire to ensure that there is a steady stream of games commencing as others finish, and/or to attract television audiences in other time zones within the country or on the other side of the world; or it may have been scheduled so as to attract and maintain the attention of an audience which can then be passed on to the next television time-slot and regime of programming, or simply to maximise advertising revenue.

If the event is particularly important (a Tri-Nations rugby international, a football World Cup match) the best seats in the house will not necessarily be made available to ordinary spectators: premium space will be reserved for corporate boxes which can be used to entertain clients, and other tickets might be distributed to companies who will sell them as part of tourism packages. This exclusivity is functions as capital, further commoditizing and enhancing the occasion and helping to attract a wider television audience. Giant screens can be set up in public places or clubs, and those crowds and their performances are then integrated into the televisual and digital network of texts. On the other hand, if the game is having trouble attracting a live crowd, tens of thousands of tickets will be distributed at schools and in shopping malls, simply to provide the semblance of atmosphere and occasion. Taken together "The net effect of this process is to reassert the hold of television over live sport, even for fans for whom its coverage is seen as banal; or technically inadequate; or both" [11].

This transformation of the time and place of spectator sport by the logics and imperatives of commercial television has had another consequence, one alluded to in Andrew Blake's previous quote: much like the newspapers of the 1890s and 1900s, television (and by extension the public relations and marketing industries) has taken on the task of widening the sports demographic, and more specifically of promoting and commoditising sport and sports consumption to groups who know little or nothing of the field, and traditionally have cared even less. To some extent this simply involves promoting sport globally to lucrative non-traditional markets (popularising men's soccer in the United States, rugby in Japan, the NFL in Europe, tennis and golf in China), as well as with regard to gender (attracting women to overtly masculinist sports such as rugby), ethnicity (in Australia, attempts have been made both to raise the profile of Australian rules football with migrant groups, and to de-ethnicise football), class (promoting cricket and rugby to a working class demographic in Britain and Australia respectively) and age (making bowls, ten pin bowling, golf and cricket appealing and relevant to younger audiences). The main BBC sports website, for instance, mixes its up-to-the-minute scores for soccer and cricket games and general sports news and opinion pieces with what can best be termed promotional 'beginners tutorials' on sports skills, usually featuring 'of the moment' performers and stars and represented in a style, and at a level, that appeals to the non-cognoscenti ('Find out how Jimmy Anderson gets his reverse swing', 'Learn to take a penalty like Ronaldo'). Basically the approach here is promotion disguised as pedagogy, much as it was in the newspapers at the beginning of the last century.

What this implies is the transformation of sport into something that requires little specialist knowledge or even interest, but which is appealing (in an almost transient manner) because it's a fashionable event that anyone could and indeed should attend, experience, be seen at and be able to talk about. Like all popular culture, sport is increasingly susceptible to, and integrated into the rhythms of, the logics of the mass media (and by extension, fashion). The mass media is part of what Bourdieu describes as the 'large-scale production' subfield of the field of cultural production, which:

involves what we sometimes refer to as 'mass' or 'popular' culture: privately owned television, most cinematic production,

radio ... Sustained by a large and complex culture industry, its dominant principles of hierarchization involve economic capital or 'the bottom line.' Its very nature ... (produces a) dependence on the broadest possible audience [12].

The close connection between sport and the mass media also produces something else: a subordination, both with regard to sports reporting and the activities and decisions taken within field of sport itself, to the "twin constraints of time and effect" (Schirato and Webb). These are, for Bourdieu, the conditions under which television, and the commercial mass media in general, operates: time, on television "is an extremely rare commodity" (Bourdieu), and media practitioners and journalists:

are carried along by the inherent exigencies of their job ...

Journalists have special 'glasses' through which they see certain things and not others, and through which they see the things they see in the special way they see them. The principle that determines this selection is the search for the sensational and the spectacular. Television calls for dramatization, in both senses of the term: it puts an event on stage, puts it into images. In doing so, it exaggerates the importance of that event [13].

Like the media and the large-scale section of the field of cultural production of which it is increasingly a part, sport must address and satisfy two main imperatives: first, appeal to the widest demographic in order to maximise revenue; second, create dramatic effects in a time-economical manner. In a sense these two imperatives are played out through and with regard to the question of spectatorship and its place and development within the field of sport. The transformation of sport from a game played by elites to that of a commodity and/as mass media event has implications not just in terms of who the field 
accepts (and what it values), but also in terms of what is expected, both of those who 'belong' to the field and those who more or less pass through as tourists. As Bourdieu writes, one only has to think of what is implied:

in the fact that a sport like rugby (in France - but the same is true of American football in the USA) has become, through television, a mass spectacle, transmitted far beyond the circle of present or past 'practitioners' ... to a public very imperfectly equipped with the specific competence needed to decipher it adequately. The 'connoisseur' has schemes of perception and appreciation which enables him to see what the layman cannot see, to perceive a necessity where the outsider sees only violence and confusion, and so to find in the promptness of a movement, in the unforeseeable inevitability of a successful combination or the near-miraculous orchestration of a team strategy, a pleasure no less intense and learned than the pleasure a music-lover derives from the particularly successful rendering of a favourite work. The more superficial the perception, the less it finds its pleasure in the spectacle contemplated in itself and for itself, and the more it is drawn to the search for the 'sensational', the cult of obvious feats and visible virtuosity and, above all, the more exclusively it is concerned with the other dimension of the sporting spectacle, suspense and anxiety as to the result, thereby encouraging players and especially organizers to aim for victory at all costs [14]

What in fact is implied here? Let's take the transformation of sport from inalienable culture (in one form or another: agonistics and/ or fair play as ethos; the privileged site of communal identity; the object of disinterested aesthetic appreciation) to a mass media service or commodity. Jean Baudrillard suggests that one of the defining characteristics of contemporary society is that we "live at the pace of objects, live to the rhythm of their ceaseless succession" [15]. As he writes: "Today it is we who watch them as they are born, grow to maturity and die, whereas in all previous civilizations it was timeless objects, instruments or monuments which outlived the generation of human beings" [16]. Much the same can be said regarding sporting teams, competitions, traditions - and even individual sports. For most of the twentieth century in the southeast of Australia, for instance, a large proportion of the working-class population grew up with an allegiance to the local rugby league side, which pre-dated them and (they presumed) would outlive them. The local sporting team was a cultural (colours, nicknames, achievements, styles of play, legendary players, rivalries) as well as a material (geographical location, stadium, transport grids that linked the area of competition) constant with which they were familiar and identified with, and through and across which they passed (as spectators, officials, players). This was a culture of continuity, familiarity, place and stasis: the movement of players between clubs, for instance, was relatively infrequent and frowned upon (although not unknown), largely because it vitiated the links between team and the person concerned, and called into question their loyalty and integrity; and fans of a particular team were rarely drawn from outside the traditional demography/geography. Moreover it was easy for fans to identify with players not only because they tended to play for the one team, but also because they were sometimes from the same area (for a time a player was only eligible to play for a side if he lived in that suburb) and usually of the same class. Moreover, this non-differentiation extended into areas such as educational level, language, income, work (players usually had fulltime jobs) and bodily shape (unlike contemporary professionals, they were not the products of weights programs).

That set of relationships and culture was on the decline by the 1960s, when live television coverage, and the media exposure and revenue it provided, started to influence salary levels, fixtures and scheduling, player movements and rules. Like American football at the beginning of the nineteenth century, rugby league was a relatively static game in which one team could easily dominate possession if good enough: accordingly during the 1960s and 1970s the rules were changed to encourage a more open, flowing, high scoring and competitive (and television-friendly) contest, awarding extra points for tries, and limiting the time in which a side could hold the ball. The traditional game-as-culture passed away completely in the 1990s, when the media proprietor Rupert Murdoch organised and financed a rival competition - dubbed 'Superleague' - which was tied to his Sky satellite sports network. After a season the two competitions merged, but Murdoch's television interests, imperatives and money, along with those of the Kerry Packer owned and terrestrial Channel Nine network, effectively owned rugby league from that point on. During and after the struggle for control of what had been a one stage a quintessential working class sport, teams that had been members of the league for most of the century were jettisoned or forced to amalgamate, and completely new sides were formed from scratch, sometimes in traditional league areas (working class Newcastle) and sometime in areas that had never supported the game (Adelaide and Melbourne, where Australian Rules dominated). The Adelaide and Melbourne sides attracted paltry crowds, but that wasn't the goal. Their complete dependence on Murdoch revenue meant that their matches could be (more or less entirely) scheduled to suit television; in short their existence was predicated on Murdoch's need to find content and fill up the time for his pay television subscribers.

This domination of commercial media logics and values in and over the field of sport has extended to supporters and spectatorship. In the nineteenth century, and even well into the twentieth, there was generally a strong connection between a team, its supporters and a specific physical location: it could be presumed, at least until the last twenty years or so, that most of the supporters of the Aston Villa (English, football), the Chicago Cubs (USA, baseball) and Footscray/ Western Bulldogs (Australian Rules) came from Birmingham and the midlands, Illinois, and the Western Suburbs of Melbourne, respectively. This is no longer the case with these and most other professional sports teams, and in certain instances it probably doesn't apply to national teams (Brazil in soccer, Fiji in rugby sevens, and formerly the West Indies in cricket). Radio and television extended the numbers of those who felt an affiliation with a team as well as a sport: children growing up in the midlands of England, Northern Ireland or Wales in the 1920s and 30s, for instance, might well bypass the family tradition of supporting the local team and identify with Herbert Chapman's glamorous Arsenal side. This process has been accentuated since the 1970s. The advent of global communication technology and transport networks (in particular satellite television and internet sports sites), the packaging and exporting of competitions (ESPN, for instance, shows live soccer games from England, Italy, Spain and Holland, as well as NBL, MLB and boxing matches) to global audiences, and increases in the number of regular (televised) international competitions and tournaments created global audiences and fan bases which may never watch their team not from the stands, but on television screens, or catch real time scores and audio-visual coverage on the internet. The Tour de France, for instance, has gone from being a predominantly French concern covered in detail only in local newspapers, to an event that is televised live globally, and has generated its own tourism phenomenon (fans travel around the route of the race following the race while seeing the country, much like the 
Barmy Army and the touring English cricket team).

This 'global turn' with regard to the development of interest in or support for teams has its precedents: after the 1958 Munich disaster, Manchester United and the 'Busby Babes' achieved a kind of media status and fan base that transcended local or national boundaries; and the style of play of the Brazilian soccer teams of the 1950s and 60s meant that Brazil came to be more or less associated with the sport. What is different now is the combination of the amount of interest and the income that it generates. Manchester United generated \$US225 million in revenue in 2002, mainly through television, sponsorship and merchandising; and has supporter groups throughout the UK as well as in Dublin, Belfast, Tokyo and Sydney [17]. Success on the field is no longer measured in traditional terms such as trophies: it now translates into and generates media interest and a concomitant fashionable status; allows clubs to raise the price of seats; helps with season ticket sales; increases the demand for corporate boxes; provides entry into lucrative international competitions; and attracts new sponsorship and naming rights money. As well as widening their support base and increasing their revenue globally, clubs have seen - or overseen - changes in other important areas such as the composition of match day crowds, marketing strategies, and their general organisational structure and functions. Spectators, for instance have:

had to pay more - much more - to be part of the live show. Poorer spectators simply couldn't afford a seat. The 'People's game' was becoming too expensive for the people ... Top clubs changed their shirt designs half a dozen times in as many years ... Clubs believed in charging what the market could bear not what fans could reasonably afford. For all the television money, the price of seats at the big clubs kept rising as fans clamoured to see the new foreign stars ... Entry to big games was increasingly restricted to ticket holders [18].

This global interest in professional sport, along with the decrease in the capacity of grounds (a result both of safety legislation and the imperative to provide more comfortable viewing conditions for the middle class/families) and a rise in the cost of attending games, means that increasingly the experience that supporters and spectators have of professional sport is one that is mediated through television, newspapers, magazines and new media (the internet, digital phones). Moreover these globally televised sporting contests are watched by audiences increasingly made up of viewers attracted to the event at the level of fashion or on a passing interest - Bourdieu's laymen and outsiders who "see only violence and confusion" [19]. Not surprisingly, this new and increasingly important type of viewer (unfamiliar with rules and traditions; illiterate and indifferent with regard to skills; inattentive and unwilling to commit much time) has exercised a considerable influence over both television (and more generally, mass media) coverage and representation of sport, and the way it is played (rules, rhythms of the game). If this viewer is unsure whether, in Bourdieu's terms, the game 'is worth the candle' [20], it is up to the media and sports administrators to ensure that it is - if only because being (even vaguely or ephemerally) attentive to the sports event provided television ratings and potential audiences for advertising.

How do these various developments (the increase in casual viewers, the dominance of commercial logics, the advent of media technologies and techniques that take you 'to the game') dispose the way sport is seen and experienced? The field of sport now has two quite distinct audiences - what Bourdieu terms 'connoisseurs' and 'laymen' [21] - that correspond roughly to the autonomous (of and for itself) and heteronomous (tied in to and with imperatives and logics from other powerful fields such as business and the media) poles of the field. The connoisseur identifies strongly with a team, almost at the level of an idealised abstraction, while the laymen will only identify with and show interest in a sport, team or player 'in passing; that is to say, when a team or sport or event is subject to significant mass media attention or promotion. Sports connoisseurs (and the ethos, attitudes and values that drive them) are in one sense becoming increasingly less important as the mass media chase the widest possible demographic; but in another sense (and simultaneously) they have become an increasingly valuable commodity, precisely because they provide the culture (an intense appreciation of and commitment to the skill, playfulness and traditions of the game) that allows the media to sell sport to the wider public as an exciting and passionate occasion.

\section{Conclusion}

There is any number of Nike television commercials that neatly encapsulate the way in which the relation between the inalienable dimension of the field of sport (as play and ethos) and its transformation into a market-driven form of mass media culture is played out. For one of these the setting is a soccer match between national teams of Brazil and Portugal. As the players walk, side-by-side, through the concrete subterranean passage that lead onto the field, the scene is clearly recognisable as early 21st century sport, one that is characterised by strong capitalist, bureaucratic and media inflections. The sides (which will have been selected by managers appointed by the respective national federations) are wearing national colours, with the shirts supplied by multinational sports companies (Brazil, for instance, have signed a long-term contract, and are closely associated, with Nike). Many of the players are instantly recognisable worldwide as both players and media stars. They are frequently the subject of news stories about transfer rumors or romances, and frequently appear in advertisements for football boots or upcoming games. Nike's choice of teams reflects those media and business logics: Brazil and Portugal, for instance, have numerous high profile footballers, and share a tradition of playing and valuing skillful, non-ends-directed football in contrast to national teams such as Germany, England and even Italy and Argentina, which have usually adopted a more cynical approach.

The occasion will be represented as an important competition match sanctioned by FIFA. The players' faces and bodies show signs of seriousness and tension: they process slowly and deliberately, stare intently ahead, and are too focused to acknowledge the other team. They emerge from the tunnel and take the field in a modern stadium (perhaps with a retractable roof) filled with as many as one hundred thousand (the capacity of the stadium having been determined, among other things, by safety regulations and requirements) seated fans who will have paid the equivalent of something in the region of hundreds (legally) and thousands (to scalpers) of US dollars a seat, depending on the importance of the match and the location of the seats. The game will be strictly circumscribed regarding temporal, spatial and material characteristics and dimensions. Action will begin, cease and recommence only when the referee blows a whistle, and will take place within a marked space commensurate with FIFA rules regarding the length and breadth of the field and its various components (the dimensions of the penalty area, the height of the goalposts). The game will usually run for ninety minutes (not including time added on for 
stoppages), even if the result is a foregone conclusion after thirty minutes and supporters of the losing team are leaving in droves. Players must wear appropriate gear: to wear the wrong coloured shorts, or only one sock, or with writing or other marks on the gear other than those of the official or recognised sponsors or makers, would result in a player being removed (temporarily or otherwise) from the field.

There will be a strict demarcation between officials and players, and players and spectators. The media may purport to 'take viewers into the middle of the action', but if a spectator somehow climbed over the partition that separated them from the players and evaded the numerous trained security staff and police and ran onto the field, then they'd be chased, apprehended, ejected from the ground and heavily fined. The crowd at the venue will be joined by hundreds of millions of viewers around the world watching and listening to it on live and delayed telecasts, through both terrestrial and satellite media, on television, radio and through the internet. A pre-game show will analyse past results, injuries and the possible influence of the referee on the outcome. Highlights of previous games will be accompanied by a plethora of statistics (team and individual) about passes-per-shot-at-goal, goals-per-game, time-in-possession, tackles, fouls, goals and assists (although this will paltry in comparison to the statistical information provided by networks covering, say, a World Series baseball game). Every significant action (offside decisions, fouls, goals) will be replayed, in slow motion and at ordinary speed and from numerous angles, both on a large screen within the stadium (broken only by sponsorship messages), and to media viewers; and remote microphones will pick up the noises and words coming from the players and officials. At halftime a panel of experts (made up of past and current players and managers, as well as journalists and media commentators) will analyse incidents, provide opinions about what is happening and why, and predict the outcome.

The match receipts will be in the tens of millions of US dollars, but this will be dwarfed by the television and internet rights, and the advertising revenue generated by board space around the ground, or the right to exclusively kit one or both teams. The players will be paid out of this revenue, as will the federations, managers, coaches, physiotherapists, doctors, publicists, agents, halftime entertainers, the singer of the respective national anthems, and the referee and linespersons. Once the game has finished, it will continue to be analysed and to generate income: television networks around the world will show highlights during the sports segment of the evening news; newspapers and magazines will write stories about the game and its dramas, heroes and villains; videos and DVDs of the game will be produced, packaged, advertised and sold. Reputations will be made and lost (with important consequences for salaries, contract extensions and sponsorship revenue), players will be induced to change clubs, and millions of fans will celebrate or drink away or violently manifest their sorrow, depending on the outcome. Politicians will line up to be photographed with the winners, and questions asked in the media and political institutions of the losing country. A government might even fall as a consequence of the result.

Little of this is actually shown in the commercial: most of it is implied through what we see in those opening shots. Sporting advertisements usually mirror or reproduce, in miniature, the field and its practices, values, rules, agents and institutions, with the stars, drama, excitement, crowd and skill of the game condensed into a few visuals. A typical football commercial would show a star like Ronaldo or Messi on the ball, a scything tackle being skillfully avoided, the winning goal blasted into the back of the net past an acrobatic goalkeeper, the celebrations of the players, the fans shouting and screaming with joy. And the name of the sponsor would be associated with the action, the players and the gear, but also with the passion, excitement and beauty of football.

But this isn't a typical sporting commercial. Let's go back to the scene we were describing: Brazil and Portugal are on their way to take part in an institutionally authorised, important and very serious sporting contest, when the players start behaving as if they were children or teenagers having a kick-about on a Brazilian beach. One player takes possession of the ball and starts playing with it - juggling it, bouncing it off walls, flicking it up into the air. The rest join in, trying to get the ball away from the first player in order to outdo his tricks. The intensity, pace and skill increases as each person ups the ante, until the action resembles a pinball game, with the ball flying in all directions. Suddenly the referee appears. He's clearly horrified by what's going on, tackles (actually fouls) the player in possession (the Brazilian Ronaldino) and retrieves the ball. The final scene shows that the order of things has been restored: the dignified looking referee holds the ball, a national anthem plays, the crowd sings, the cameras pan across the players who are now literally back in line, hands behind their backs. They are blackened, dirty and chastened, but focused and in possession of themselves: playtime is over, and sport takes its place.

This commercial represents, and is a manifestation of, the transformation of the field of sport and its activities into a form of popular culture closely tied in with, and in many ways indistinguishable from, the values, logics and discourses associated with the global commercial mass media. The field continues to produce a discursive commitment to, and perform in accordance with, the notion of the inalienable (play and the sporting ethos), but its status is that of a media fantasy and a commodity. Ironically, the contemporary mass media-dominated field of sport increasingly finds itself producing performances that sport is more than just an extension of the commercial mass media, and of its commitment to the idea and ethos that, at heart, sport is still people at play.

\section{Competing Interests}

The authors declare that they have no competing interest.

\section{References}

1. Bourdieu, P. 'Sport and Social Class', in Mukerji, C. \& Schudson, M. (eds) Rethinking Popular Culture, Berkeley: University of California Press, 1991. p366.

2. Bourdieu, P. 'Sport and Social Class', in Mukerji, C. \& Schudson, M. (eds) Rethinking Popular Culture, Berkeley: University of California Press, 1991. p366.

3. Guttmann, A. Sports Spectators, New York: Columbia University Press; 1986. p134.

4. Hill, J. Sport, Leisure \& Culture in Twentieth Century Britain, New York: Palgrave; 2002. p103

5. Guttmann, A. Sports Spectators, New York: Columbia University Press; 1986. p135.

6. Polley, M. Moving the Goalposts, London: Routledge; 1998. p71.

7. Polley, M. Moving the Goalposts, London: Routledge; 1998. p72 
Citation: Schirato T, Zhang N (2015) Contemporary Sport as Media Spectacle: Mass Media and the Transformation of the Field of Sport. Int J Journalism Mass Comm 1: 112. doi: https://doi.org/10.15344/2349-2635/2015/112

8. Guttmann, A. Sports Spectators, New York: Columbia University Press; 1986. p135

9. Gaffney, C. \& Bale, J. 'Sensing the Stadium' in Vertinsky, P. \& Bale, J. (eds) Sites of Sport, London: Routledge; 2004. pp27-8

10. Baudrillard, J. The Consumer Society, London: Sage; 2003.

11. Blake, A. (1996) Body Language: the Meaning of Modern Sport, London: Lawrence \& Wishart; 1996. p168

12. Bourdieu, P. The Field of Cultural Production, Cambridge: Polity Press; 1993. p16

13. Bourdieu, P. On Television and Journalism, London: Pluto Press; 1998. p19

14. Bourdieu, P. 'Sport and Social Class', in Mukerji, C. \& Schudson, M. (eds) Rethinking Popular Culture, Berkeley: University of California Press, 1991. p366

15. Baudrillard, J. The Consumer Society, London: Sage; 2003. p25

16. Baudrillard, J. The Consumer Society, London: Sage; 2003. p25

17. Polley, M. Moving the Goalposts, London: Routledge; 1998. p78

18. Holt, R. \& Mason, T. Sport in Britain: 1945-2000, Oxford: Blackwell; 2000. pp106-7

19. Bourdieu, P. 'Sport and Social Class', in Mukerji, C. \& Schudson, M. (eds) Rethinking Popular Culture, Berkeley: University of California Press, 1991. p366

20. Bourdieu, P. Pascalian Meditations, Cambridge: Polity Press; 2000.

21. Bourdieu, P. 'Sport and Social Class', in Mukerji, C. \& Schudson, M. (eds) Rethinking Popular Culture, Berkeley: University of California Press, 1991. p364 